The Indexing of Books and Periodicals. By Dr. John W. T. Walsh. Pp. 118. (London : Edward Arnold and Co., 1930.) 6s. net.

IT cannot yet be said that the good index is the general rule, whether for books or for periodical literature, and no reader of NATURE will regard a new book on the subject as superfluous. Dr. Walsh's book does not deal with main theoretical principles, and contains little that is new for actual practice; but the main features that make for good indexing cannot be repeated too often, and they are here, on the whole, set out with due emphasis.

Dr. Walsh is, however, not always clear in his directions. For example, an alphabetical series such as "Cat, Domestic-Catfish-Catgut-Cat skins " is characterised as most undesirable on one page, but appears to be justified by the rule given on the next. And why does Dr. Walsh say that the most suitable form of index for 'abstract' journals is the classified form, with a reference to the Brussels decimal scheme? It is not easy to see why this type of journal should be placed for this purpose in a class by itself, and why the alphabetical arrangement should here be discarded. It may be advisable for the abstracts themselves to be arranged in class order, for they are designed to be used at the moment of publication as a survey of the current literature of their subject. But for the annual index, which is only as a rule a finding tool for some specific feature and ought not to take the place of a 'contents list' (as Dr. Walsh rightly points out), the arrangement would be most inconvenient. In any case the inclusion of the suggestion without elaboration will only confuse the class of reader for whom this book is designed.

The author has evidently read widely on his subject, but seems to have been unduly influenced by works on general cataloguing and classification, which have to some extent obscured for him the real nature and function of the index. For all that, the book is a practical manual which contains much that will help the inexperienced.

God: in Christian Thought and Experience. By the Rev. W. R. Matthews. (Library of Constructive Theology.) Pp. xix +283 . (London: Nisbet and Co., Ltd., 1930.) 10s. 6d. net.

"To a discerning eye", says Dr. Matthews in his preface, "it must be clear that the main question which is being decided in the world to-day, is whether or not the majority of men shall continue to believe in God." One of the difficulties with which the would-be constructor of a tenable theistic theory is faced is the absence of any generally accepted philosophy. All we can boast is " a generally accepted body of knowledge which stands for the modern world as solid and unquestionable as the logic and metaphysic of Aristotle stood for the later Middle Ages ", that is to say, natural science. Yet science does not seem able to provide us with any solution of ultimate problems. Here it leaves us unsatisfied.

There is scope, then, for someone who, starting from the commonly accepted results of natural science, will tell us as much as he can from that point of view, and indicate exactly what we must not hope to learn from him. Dr. Matthews does not claim to attack the problem from this end; he takes as his starting-point " the Christian experience of God ", and tries, in view of it, to formulate a theory of the divine nature which may be acceptable to the reason, and not contradictory to the knowledge, of modern men. Thus his book will interest theologians more than men of science. Yet scientific workers may well acclaim any work which will enlighten theologians; and this the present volume can scarcely fail to do.

\section{Philosophy and Psychology.}

(1) The Psychology of Insanity. By Dr. Bernard Hart. (The Cambridge Manuals of Science and Literature.) Fourth edition. Pp. xxxv +176 . (Cambridge: At the University Press, 1930.) $3 s$. net.

(2) Psychopathology : its Development and its Place in Medicine. By Dr. Bernard Hart. Second edition. Pp. vii +178 . (Cambridge: At the University Press, 1929.) $8 s .6 d$. net.

(1) Dr. Bernard HarT's little book has been reprinted almost annually since 1918 , and now we have a new edition, the fourth. The book gives an extraordinarily good account of insanity and may well be read by any educated layman, particularly the social worker, with great benefit. Hart explains mental mechanisms like projections, which are of such common occurrence in the everyday life of the normal ' man in the street'. This edition has had an introduction specially written for it, in which Hart gives a brief historical account of the influence of Janet but more particularly of Freud. He points out how Freud's views have been developed and extended, although the original ideas remain much the same. We cannot help thinking that everyone ought to read this book, and that the mental hygiene of the community would benefit by it.

(2) In "Psychopathology" Dr. Bernard Hart presents us with his Goulstonian Lectures delivered in 1926, with the addition of three chapters : one on the psychology of rumour, one on the methods of psychotherapy, and one on the conception of dissociation. These last three papers had all been published already. Dr. Hart naturally devotes a large amount of his space to the views of Freud. $\mathrm{He}$ also amply considers the views of Jung, but unfortunately appears to have little use for the theories of Adler. These, we think, might have been given more space, as they appeal to quite a number of clinicians who do not accept Freud's all-embracing use of the word sex.

Lectures on Ethics. By Immanuel Kant. Translated from the German by Louis Infield. Pp. xiv +253 . (London: Methuen and Co., Ltd., 1930.) 10s. $6 d$. net.

IT is much to be hoped that this little book will attain a wide circulation. It has several points of special interest, besides being a short handbook of practical morals, easily and pointedly written and with clear anticipation of the great thinker's main construction of ethics, which followed shortly after- 